\title{
Comparative catalytic activity of PET track-etched membranes with embedded silver and gold nanotubes
}

\section{Anastassiya Mashentseva ${ }^{\text {a,b* }}$, Daryn Borgekov ${ }^{\text {a,b }}$, Sergey Kislitsyn ${ }^{\text {a }}$, Maxim Zdorovets ${ }^{\text {a,b }}$, Anastassiya Migunova $^{\mathrm{a}}$}

\author{
${ }^{a}$ Institute of Nuclear Physics, Ibragimov St. 1, 050032 Almaty, Kazakhstan \\ ${ }^{\mathrm{b}}$ L.N. Gumilyov Eurasian National University, 5 Munaitpassov Str., 010008 Astana, Kazakhstan
}

Corresponding author. $+7(7172) 341657 * 122$; Fax: $+7(7172) 342074$. E-mail address: mashentseva.a@gmail.com

\begin{abstract}
Irradiated by heavy ions nanoporous polyethylene terephthalate track-etched membranes (PET TeMs) after ${ }^{+15} \mathrm{Kr}^{84}$ ions bombardment $\left(1.75 \mathrm{MeV} /\right.$ nucl with the ion fluency of $\left.1 \times 10^{9} \mathrm{~cm}^{-2}\right)$ and sequential etching was applied in this research as a template for development of composites with catalytically enriched properties. A highly ordered silver and gold nanotubes arrays were embedded in $100 \mathrm{~nm}$ pores of PET TeMs via electroless deposition technique at $4^{\circ} \mathrm{C}$ during $1 \mathrm{~h}$.

All "as-prepared" composites were examined for catalytic activity using reduction of 4-nitrophenol (4-NP) to 4-aminophenol (4-AP) by sodium borohydride as a common reaction to test metallic nanostructures catalysts. The effect of temperature on the catalytic activity was investigated in range of $292-313 \mathrm{~K}$ and activation energy were calculated. $\mathrm{K}_{\text {app }}$ of Ag/PET composites linearly increase with an increase of the temperature thus normal Arrhenius behavior have been seen and the activation energy was calculated to be $42.13 \mathrm{~kJ} / \mathrm{mol}$. Au/PET composites exhibit not only more powerful catalytic activity but also non-linear dependence of rate constant from temperature. $\mathrm{K}_{\text {app }}$ increased with increasing temperature throughout the 292-308 $\mathrm{K}$ temperature range; the reaction had an activation energy $65.32 \mathrm{~kJ} / \mathrm{mol}$. In range $311-313 \mathrm{~K}$ rate constant dramatically decreased and the apparent activation energy at this temperature rang was $-91.44 \mathrm{~kJ} / \mathrm{mol}$ due some structural changes, i.e. agglomeration of Au nanoparticles on the surface of composite.
\end{abstract}

Keywords: track-etch membranes, electroless deposition, gold and silver nanotubes, temperaturedependent catalytic activity.

\section{Introduction}

Noble gold and silver nanotubes (NTs) embedded in porous matrices are an important class of functional composites and have attracted significant attention in recent time because of their unique properties and prospective application as electrochemical electrodes [1-2] or sensors [3-5], heterogeneous catalysts [6-7] and flowthrough reactors [8] as well as in medicine [9-10].

A number of different techniques to create "silver/gold metallic nanoparticles-polymer" composites were described in the literature [11]. One of the most popular approaches is based on metal ions implantation of polymer matrix [12-13]. This technique allows prepare composites with small size distribution of nanoparticles, but from another hand it has major restriction such as complicated equipment and special conditions to prevent heating of film during implantation process. Templateassisted electroless deposition technique applied in this study is a very simple and elegant approach to create polymer composites with embedded nanostructures because of its low cost, inherent selectivity and its simplicity can facilitate the large-scale production of nanotube-nanoparticle hybrids [14].

Nanoporous track-etched membranes are universe support for noble nanosized catalysts due several reasons: the internal pores provide a large surface area and more effective loading of the catalytic material [15]; there is no need to separate the catalyst from reaction mixture after reaction was completed and finally catalytic reactions could be occurred on the surface of membrane as well as through them [16]. Also, flexible polymer template could be easily removed and cleaned without 
contaminating and morphologically changing the nanostructures formed and further applied as catalyst for several times.

Recently, there have been several reports that demonstrated the supported gold and silver nanoparticles (NPs) and NTS as the catalyst for reduction of the wide range of the nitroaromatic compounds [8], CO oxidation [17] et al. However, the most popular model reaction to test the catalytic properties of nanosized heterogeneous catalysts is the single-step catalytic hydrogenation of p-nitrophenol (4-NP) to p-aminophenol (4-AP) by sodium borohydride as the reducing agent in aqueous solution [18-19]. The kinetic and of this bench-mark reaction was recent detailed by S.Wunder et al. [20-21] and the most suggested mechanism for this reaction is the Langmuir-Hinshelwood mechanism that requires the both a 4-NP and activated hydrogen species to be present on the surface simultaneously to react. To the best of our knowledge, very few reports have been published there the dependence of the rate constant of this reaction on temperature only for supported $\mathrm{Au}$ [21] and Ag [22] nanoparticles therefore the temperature dependent activity of the TeMs-based nanocomposites with embedded noble NTs have not been studied enough.

Here we report our recent research activities on the fabrication of embedded Au and Ag NTs arrays in nanoporous PET TeMs template together with comparative elucidation of the catalytic activity of prepared composites for reduction of p-nitrophenol in temperature range of 292-313 K.

\section{Experiment}

Deionized water (18 $\mathrm{M} \Omega \mathrm{cm}$ at room temperature) was used in experimental procedures. All chemicals were applied without additional purification and all solutions were freshly prepared.

\section{Template preparation and metal deposition}

PET film (Hostaphan ${ }^{\circledR}$ RNK, Mitsubishi Polyester Film, nominal thickness $12 \mu \mathrm{m}$ ) was irradiated with $\mathrm{Kr}$ ions (energy: $1.75 \mathrm{MeV}$ per nucleon; the ion fluency of $1 \times 10^{9} \mathrm{per} \mathrm{cm}^{2}$ ) at the DC-60 cyclotron in Astana and etched in sodium hydroxide solution $\left(2,2 \mathrm{M}\right.$ at $85^{\circ} \mathrm{C}$ for $75 \mathrm{sec}$ that provide formation of the $100 \pm 5 \mathrm{~nm}$ cylindrical pores). The effective pore sizes of parent template as well as the inner diameter of embedded NTs were estimated by gas (compressed air was applied) permeability technique using Hagen-Poiseuille equation.

The improved electroless deposition technique reported by F.Muench [23] was used for Ag/PET preparation and plating solutions containing $\mathrm{AgNO}_{3}(17 \mathrm{mM})$, potassium sodium tartrate $(120 \mathrm{mM})$ and pyridine $(50 \mathrm{mM})$ as a complexing agent was applied.

Gold deposition from sulphite plating solution was performed according to the standard technique described by Martin et al. [24].

In all experiments deposition took place at $4{ }^{\circ} \mathrm{C}$ within $1 \mathrm{~h}$ afterward composite membranes Au/PET and $\mathrm{Ag} / \mathrm{PET}$ were washed in water and ethanol and dried with air.

\section{Characterisation}

Scanning electron microscopy (SEM) and energy-dispersive X-ray spectroscopy (EDAX) were performed using a JEOL-7500F (JEOL, Japan) equipped with iXRF EDS -2000 (Oxford Instruments). Prior to the measurement, the PET template was removed with 1,1,1,3,3,3-hexafluoro-2-propanol and template-free NTs were collected on the carbon tape sputter-coated with gold.

X-ray diffraction (XRD) patterns of "as-prepared" samples were obtained on a D8 Advance (Bruker, Germany) to study the crystalline structure with a fixed anode $\mathrm{Cu}$ source. X-ray was generated at 40 $\mathrm{mA}$ and $40 \mathrm{kV}$ and the scanning position ranged from $15-90^{\circ} 2(\theta)$. The crystal grain sizes of samples were calculated from the diffractogram peak shape using Scherrer equation.

\section{Catalytic reaction}

The catalytic activity of "as-prepared" $\mathrm{Ag} / \mathrm{PET}$ and Au/PET composite membranes was determined by a reduction of 4-NP to 4-AP by $\mathrm{NaBH}_{4}$ according to the experimental procedure described in [6]: Afterward the sample of Ag/PET composites (size of tested sample $-5 \times 5 \mathrm{~cm}$ was a similar in all 
experiments) was immersed in a beaker and catalytic activity was monitored every 5 minute absorbance measurements at Specord-250 spectrophotometer (Jena Analytic, Germany) by recording rinsed with deionized water and used in the next 4 cycles without any additional pretreatment.

\section{Results and discussion}

By low-temperature electroless deposition technique we were able to prepare a series of PET TeMs with embedded gold and silver nanotubes. Figure 1, parts a-b, shows SEM images of synthesized composite membranes as well as cross-sectional view of silver and gold NTs arrays after template dissolving (Fig.1, parts c-d). As it is seen, the obtained nanostructures have a tubular morphology and are uniform in terms of their length $(12 \mu \mathrm{m})$. The inner diameter of the silver and gold nanotube walls was determined to be about $60 \pm 4.2$ and $58.1 \pm 0.8 \mathrm{~nm}$ respectively.
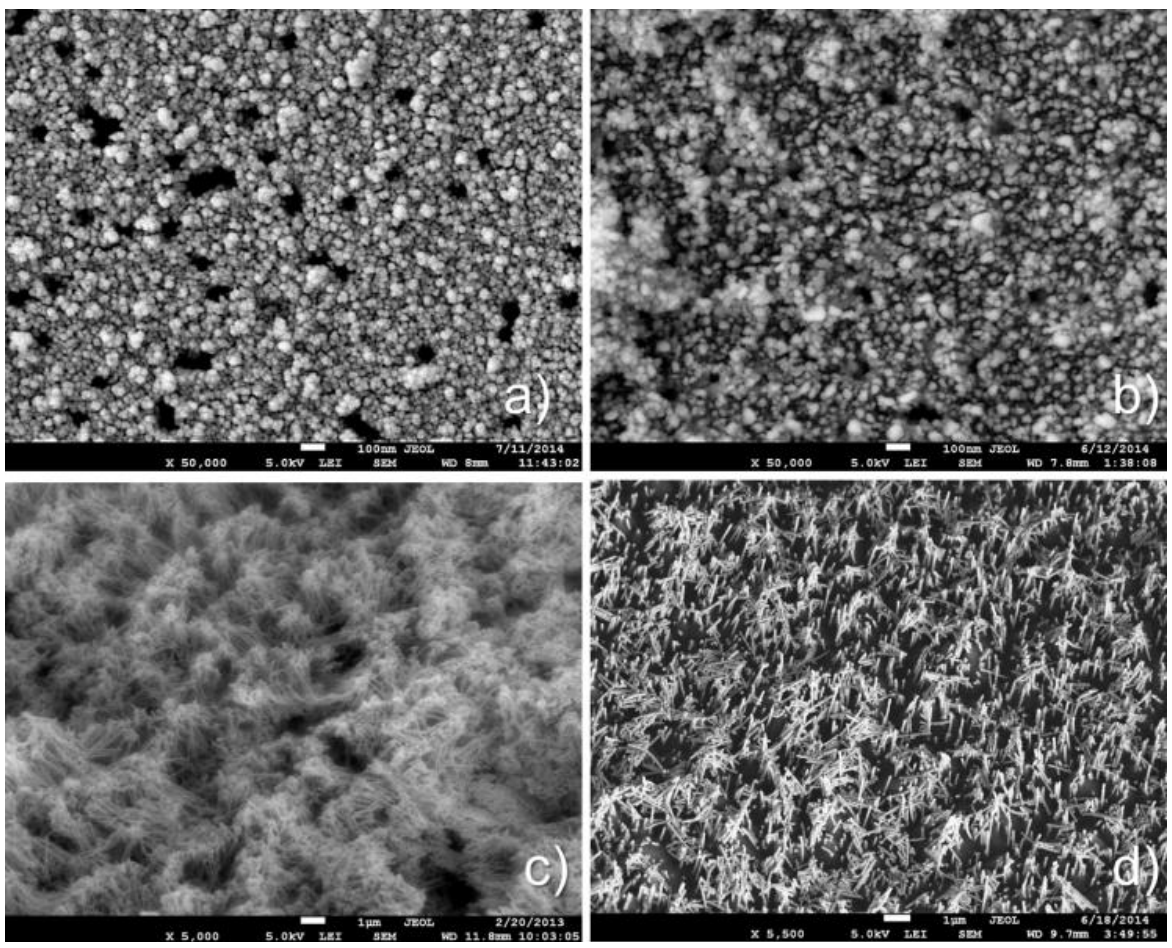

Fig.1. A closer surface view of a Au/PET (a) and Ag/PET composites and SEM images of templatefree gold (c) and silver (d) NTs arrays electrolessly deposited on PET TeMs

XRD analysis was used to characterize the chemical composition and crystal structure of prepared composites. X-ray diffraction patterns were obtained over the Au/PET composite (Fig. 2a) and shows four characteristic peaks $\left(38.1^{\circ}, 44.3^{\circ}, 64.5^{\circ}\right.$ and $\left.77.5^{\circ}\right)$ due to silver crystalline structure and in addition a broad peaks in the region $15^{\circ}$ to $26^{\circ}$ due to the amorphous structure of polyethylene terephthalate template. The grain size of the silver nanoparticle on the surface of composite was calculated from the line broadening using the Scherrer's formula (Table 1). The sizes were calculated from all the four peaks and average diameter was found to be $d=14.5 \pm 2.7 \mathrm{~nm}$. The bottom blue vertical lines on Fig.2 show the peak positions and relative intensities of pure powder Ag (JCPDS 40783), red lines correspond to Au standard (JCPDS 4-0784). 


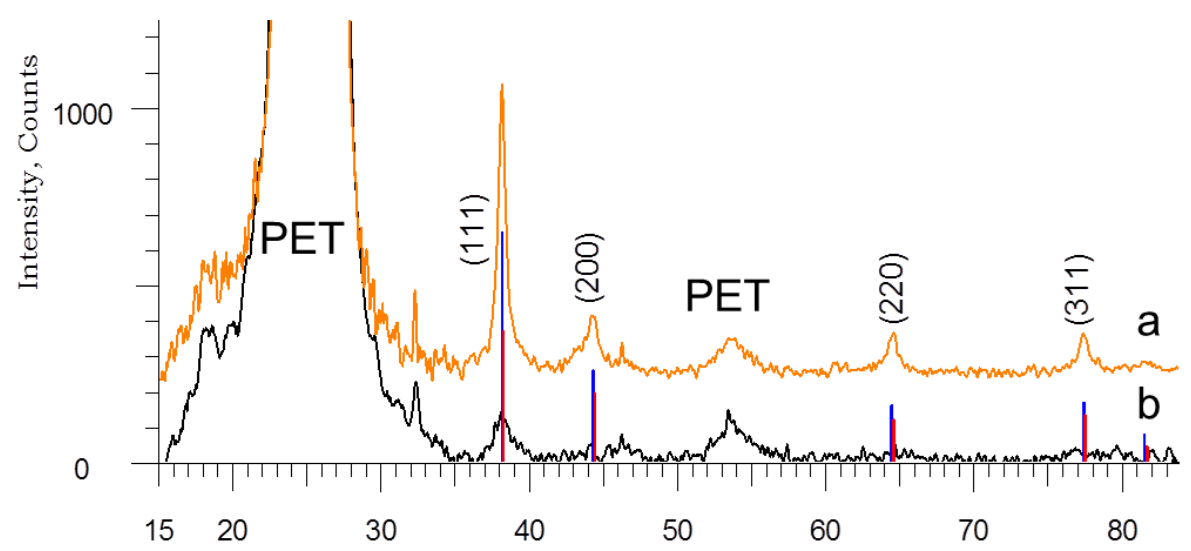

Fig.2. XRD pattern of Ag/PET (a) and Au/PET (b) composites

The significant diffraction peak Au/PET samples is broadening and the corresponding low intensity of the signal were due to more smaller size of the gold nanoparticles on the surface of composites than $\mathrm{Ag} / \mathrm{PET}$ samples and the average dimension of the Au nanoparticles on the surface of composites was estimated as $d=7.34 \pm 1.1 \mathrm{~nm}$.

Table 1. Ag/PET and Au/PET composites 2( $\theta)$ peak positions, calculated crystal sizes (d) and corresponding planes

\begin{tabular}{|c|c|c|c|c|c|c|}
\hline Sample & $\begin{array}{c}2(\theta), \\
\text { degrees }\end{array}$ & hkl & $\begin{array}{r}\text { FWHM, } \\
\text { degrees }\end{array}$ & $d, \mathrm{~nm}$ & $\begin{array}{c}\text { Average size, } d \\
\mathrm{~nm}\end{array}$ & $\underset{\AA}{\text { Cell parameter } a,}$ \\
\hline \multirow{4}{*}{$\mathrm{Ag} / \mathrm{PET}$} & 38,11 & 111 & 0,580 & 15,13 & \multirow{4}{*}{$14,5 \pm 2.7$} & \multirow{4}{*}{4,0836} \\
\hline & 44,26 & 200 & 0,849 & 10,55 & & \\
\hline & 64,54 & 220 & 0,606 & 16,19 & & \\
\hline & 77,45 & 311 & 0,653 & 16,29 & & \\
\hline \multirow{4}{*}{$\mathrm{Au} / \mathrm{PET}$} & 38,14 & 111 & 1,071 & 8,20 & \multirow{4}{*}{$7.3 \pm 1.1$} & \multirow{4}{*}{4,0801} \\
\hline & 44,42 & 200 & 1,545 & 5,80 & & \\
\hline & 64,25 & 220 & 1,335 & 7,34 & & \\
\hline & 77,74 & 311 & 1,349 & 7,90 & & \\
\hline
\end{tabular}

In order to investigate the effect of temperature on the reduction of 4-NP in aqueos solution catalized by studied composites, the experiments with different temperature (292 -313 K) were setup. It should be noted that reduction of 4-NP occur without catalysts and optical dencity of mixture did not changed within $120 \mathrm{~h}$. The progress in catalytic reduction of 4-NP on the surface of developed composites was monitored by the decrease in the absorbance at $299 \mathrm{~nm}$ (characteristic absorbance peak of 4-AP). Figure 3 shows the experimental results obtained from the reaction conducted at different temperatures.

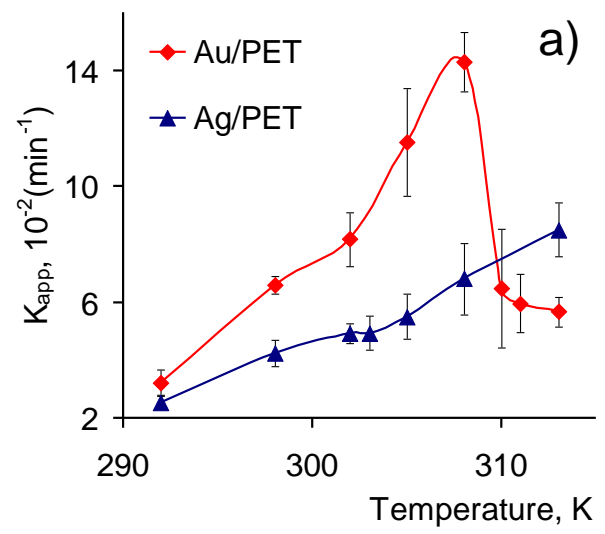




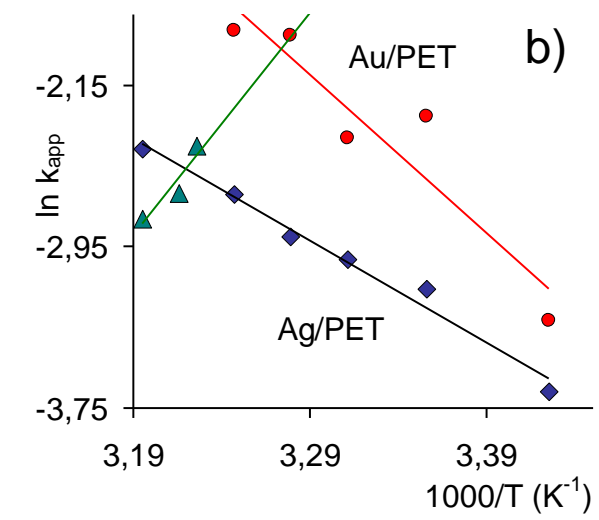

Fig.3. Effect of temperature on the reduction of 4-NP by composites based on PET TeMs with embedded gold and silver NTs (a) and Arrhenius plot for studied reaction (b)

Clearly the values of $\mathrm{k}_{\text {app }}$ of $\mathrm{Ag} / \mathrm{PET}$ composites linearly increase with an increase of the temperature thus normal Arrhenius behavior have been seen. From the set of kinetic data and by using the Arrhenius equation, the activation energy was calculated to be $42.13 \mathrm{~kJ} / \mathrm{mol}$. Highest value of $\mathrm{k}_{\mathrm{app}}=8.5 \times 10^{-2} \mathrm{~min}^{-1}$ was observed at $313 \mathrm{~K}$. Although direct comparison with similar results, published in previous reports dedicated to TEMs coated with silver as a nanosized catalysts for reduction of 4-NP is difficult due inconsistent reaction conditions such as concentration of initial chemicals, type and size of silver catalyst (i.e. NPs, nanowires or NTs), range of testing temperature. Thus, for silver NPs with diameter of 7-15 nm [25] an activation energy was found to be $E_{A}=41 \mathrm{~kJ} / \mathrm{mol}$, while for Ag supported nanoclasters $E_{A}=55.6 \mathrm{~kJ} / \mathrm{mol}$ [26], for $10 \mathrm{~nm}$ silver NPs deposited into polyaniline bridged silica networks the activation energy was claimed to be $\mathrm{E}_{\mathrm{A}}=192 \mathrm{~kJ} / \mathrm{mol}$ [27].

$\mathrm{Au} / \mathrm{PET}$ composites exhibit not only more powerful catalytic activity than Ag/PET composites but also non-linear dependence of rate constant from operating temperature: $\mathrm{k}_{\mathrm{app}}$ increased with increasing temperature throughout the $292-308 \mathrm{~K}$ temperature range $\left(\mathrm{k}_{\mathrm{app}}=15.32 \times 10^{-2} \mathrm{~min}^{-1}\right.$ for $\left.308 \mathrm{~K}\right)$ and reaction had activation energy $65.32 \mathrm{~kJ} / \mathrm{mol}$. In range $310-313 \mathrm{~K}$ rate constant dramatically decreased; at $313 \mathrm{~K}\left(\mathrm{k}_{\mathrm{app}}=6.0 \times 10^{-2} \mathrm{~min}^{-1}\right)$ the rate was even lower than that of $298 \mathrm{~K}$. The activation energy was calculated to be negative $-91.44 \mathrm{~kJ} / \mathrm{mol}$ at temperature ranging from $310-313 \mathrm{~K}$.

The observation of decreasing catalytic activity with increasing temperature appears at first to logically suggest the possibility of some structural changes in the Au/PET catalyst in particular it may be caused by changing of the Au nanoparticles size on the surface/channels of the composite membrane [28]. Another explanation for the negative gradient of the reaction curve in the temperature range of 308$313 \mathrm{~K}$ can be explained by removal of the active gold nanoparticles with the smallest diameter from the surface of the composite membrane since reaction is carried out under vigorous stirring [29].

In order to confirm whether the increase of temperature affect $\mathrm{Au}$ nanoparticles removal and aggregation the XRD analysis were carried out immediately after 1-st cycle of testing was done. As it was determined from Scherrer equation, Au crystallites sizes were slightly increased, thus after testing at $298 \mathrm{~K} \mathrm{~d}=6.99 \mathrm{~nm}$, after treatment at $308 \mathrm{~K}$ and $313 \mathrm{~K}$ diameter of crystallites was increased up to 9.44 and $10.35 \mathrm{~nm}$ respectively. SEM images in Figure 4 is suggesting a decreasing size of the gold nanoparticles after reaction at $313 \mathrm{~K}$ (Fig. 4b) compared with Au/PET sample after reaction at $308 \mathrm{~K}$ (Fig. 4a). 

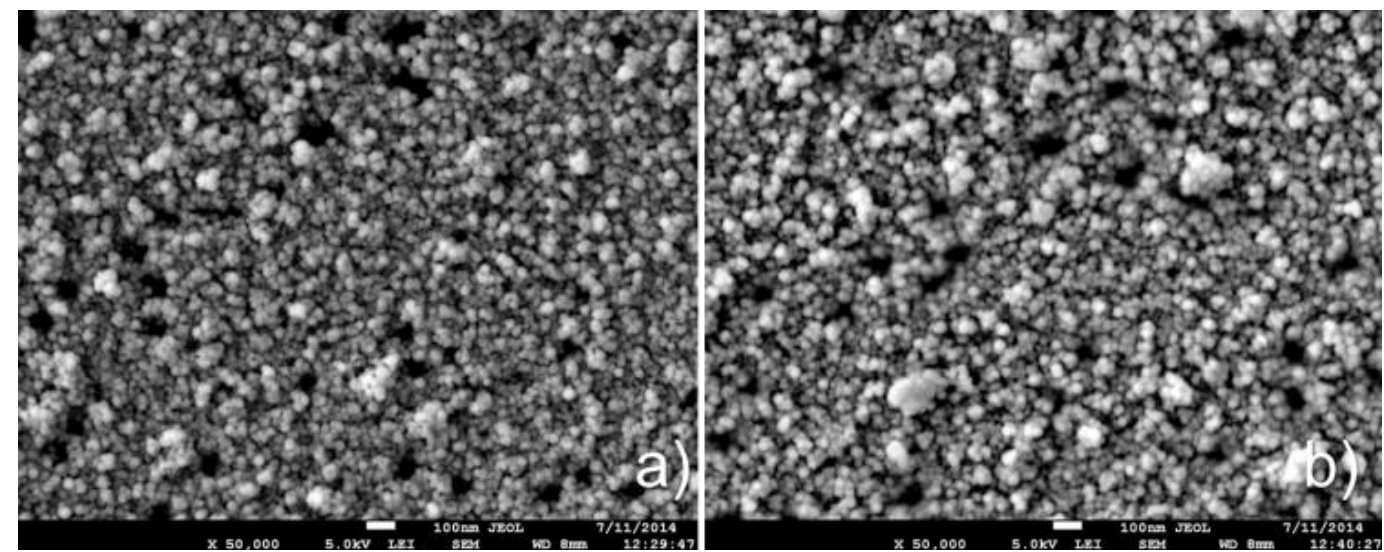

Fig.4. SEM images of surface of Au/PET composites after 4-NP reduction at $308 \mathrm{~K}$ (a) and $313 \mathrm{~K}$ (b)

Stability and reusability are a great importance for the practical application of catalysts [30]. Nonsupported nanoparticles before re-loading have to be separated from solution via filtration, sedimentation, and centrifugation, which are both time-consuming and uneconomic. Flexible TeMs could be easily removed after reaction and reusable again (after thoroughly washing with deionized water) without any addition activation procedure. The reusability of prepared Au/PET composites as sample with highest constant rate was checked at $308 \mathrm{~K}$ consecutively for 6 times. Thus, reaction time was increased from 25 minutes (1-3 cycles) up to 60 minutes for 5-th cycle and apparent constant rate is decreased in 8 times (Fig.5).

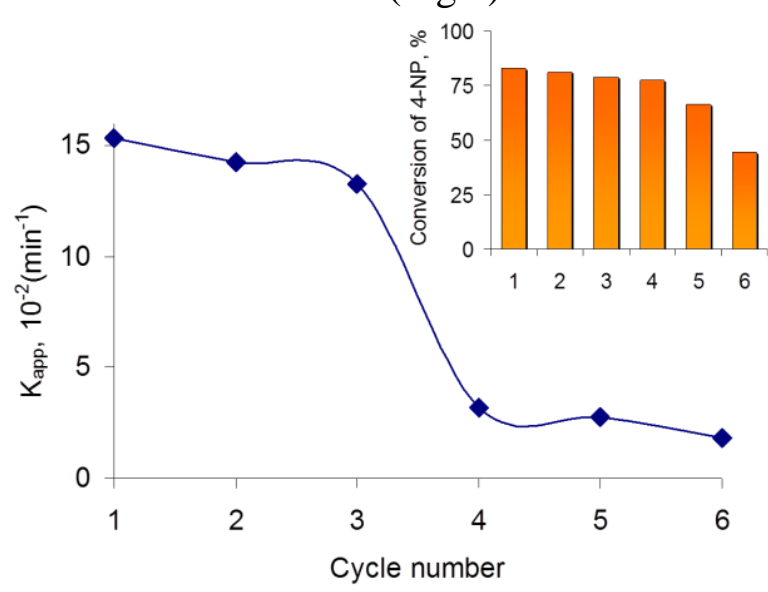

Fig.5. Changing of $\mathrm{k}_{\text {app }}$ for six successive reaction cycles with Au/PET membrane composite at $308 \mathrm{~K}$. Inset shows conversion of 4-NP for all tested cycles.

\section{Conclusions}

In this paper an efficient, reusable and separable $\mathrm{Ag} / \mathrm{PET}$ and $\mathrm{Au} / \mathrm{PET}$ composites were prepared by electroless deposition of metals within the $100 \mathrm{~nm}$ pores of a track-etched PET membrane and their characteristics are examined by SEM and XRD analysis. Catalytic ability of "as-prepared" composites were investigated in the reduction reaction of 4-nitrophenol to 4-amonophenol by $\mathrm{NaBH}_{4}$. The temperature-dependent apparent rate constant of this reaction have been studied in the temperature range of 292-313 K. In case of applying Ag/PET composites rate constant was enhanced by increasing temperature with the activation energy of $42.13 \mathrm{~kJ} / \mathrm{mol}$. More powerful and catalytic activity was demonstrated for Au/PET composites. Negative gradient of the reaction curve in the temperature range of $308-313 \mathrm{~K}\left(\mathrm{E}_{\mathrm{A}}=-91.44 \mathrm{~kJ} / \mathrm{mol}\right)$ could be caused by agglomeration of Au nanoparticles as well as their removal during intensive stirring. In addition all tested composites exhibited quite good stability: their activity had no significant decrease after reuse at least 5 cycles.

\section{Acknowledgments}

This work is supported by an International scientific technical centre (project K-2051). 


\section{References}

[1] Y.B. Mollamahalle, M. Ghorbani, A. Dolati, Electrochim. Acta, 75 (2012) 157.

[2] M. Wirtz and Ch.R. Martin, Adv. Mater., 15 (2003) 455.

[3] E-M. Felix, F.Muench and W. Ensinger, RSC Adv., 4 (2014) 24504.

[4] M. Yang, K.G. Lee, J.W.Kim et al. RSC Adv., 4, (2014) 40286.

[5] S. Siwy, L. Trofin et al. J. Am. Chem. Soc., 127 (2005) 5000.

[6] Y. Yu, K. Kant, J.G. Shapter, Microporous Mesoporous Mat., 153, (2012) 131.

[7] A. Mashentseva, D. Borgekov et al., Acta Phys. Pol. A, 125 (2014) 1263.

[8] D.M. Dotzauer, S. Bhattacharjee, Y. Wen, M. L. Bruening, Langmuir, 25 (2009) 1865.

[9] S. Yu, S.B. Lee and Ch.R. Martin, Anal. Chem., 75 (2003) 1239.

[10] Md. A. Rahman, J.I. Son et al., Anal. Chem., 81 (2009) 6604.

[11] A. L. Stepanov, NATO Science Peace S., (2009) 153

[12] G. Maggioni, A. Vomiero et al., Appl. Phys. Lett., 85 (2004) 5712.

[13] A.L.Stepanov, S.N.Abdullin et al., Phil. Mag. B, 80 (2000) 23.

[14] R.C.Martin et al. Chem. Mater., 8 (1996) 1739.

[15] D.M. Dotzauer, A.Abusaloua et al. Appl. Cat.B., 91 (2009) 180.

[16] F. Muench, M. Oezaslan et al. J. Power Sources, 222 (2013) 243.

[17] M.A. Sanchez-Castillo, C. Couto et al., Angew. Chem. Int. Ed., 43 (2004) 1140.

[18] Z.D. Pozun et al., J. Phys. Chem. C, 117 (2013), 7598.

[19] F. Muench, S. Lauterbach, H-J. Kleebe, W. Ensinger, e-J. Surf. Sci. Nanotech., 10 (2012) 578.

[20] S. Gu, S. Wunder, Y.Lu and M. Ballauff, J. Phys. Chem. C, 118 (2014), 18618.

[21] S. Wunder, Y.Lu, M. Albrecht and M. Ballauff, ACS Catal., 1 (2011) 908.

[22] K.S.Shin, J-Y. Choi et al., Catal. Lett., 133 (2009) 1.

[23] F. Muench, M. Rauber et. al., Nanotechnol., 22 (2011) 415602.

[24] L.T. Sexton, L.P. Horne, Ch.R. Martin, Mol. BioSyst. 3 (2007) 667.

[25] N. Pradhan, A. Pal, T. Pal, Colloid Surface A, 196 (2002) 247.

[26] A. Leelavathi, T.U.B. Rao, T. Pradeep, Nanoscale Res. Lett., 6 (2011) 123.

[27] K.M. Manesh, A.I. Gopalan, K.-P. Lee, S. Komathi, Catal. Commun., 11 (2010) 193.

[28] X. Zhou, W.Xu et al., J. Am. Chem., Soc., 132 (2010) 138.

[29] D.A.H. Cunnigham, W.Wogel and M,Haruta, Catal. Lett., 63 (1999) 43.

[30] X. Yang, H. Zhong et al., J. Mater. Chem. A, 2 (2014) 9040. 


\section{List of tables}

Table 1. Ag/PET and Au/PET composites 2( $\theta)$ peak positions, calculated crystal sizes (d) and corresponding planes

Table 1.

\begin{tabular}{|c|c|c|c|c|c|c|}
\hline Sample & $\begin{array}{c}2(\theta), \\
\text { degrees }\end{array}$ & hkl & $\begin{array}{r}\text { FWHM, } \\
\text { degrees }\end{array}$ & $d, \mathrm{~nm}$ & $\begin{array}{c}\text { Average size, } d \\
\mathrm{~nm}\end{array}$ & 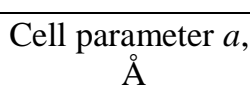 \\
\hline \multirow{4}{*}{$\mathrm{Ag} / \mathrm{PET}$} & 38,11 & 111 & 0,580 & 15,13 & \multirow{4}{*}{$14,5 \pm 2.7$} & \multirow{4}{*}{4,0836} \\
\hline & 44,26 & 200 & 0,849 & 10,55 & & \\
\hline & 64,54 & 220 & 0,606 & 16,19 & & \\
\hline & 77,45 & 311 & 0,653 & 16,29 & & \\
\hline \multirow{4}{*}{$\mathrm{Au} / \mathrm{PET}$} & 38,14 & 111 & 1,071 & 8,20 & \multirow{4}{*}{$7.3 \pm 1.1$} & \multirow{4}{*}{4,0801} \\
\hline & 44,42 & 200 & 1,545 & 5,80 & & \\
\hline & 64,25 & 220 & 1,335 & 7,34 & & \\
\hline & 77,74 & 311 & 1,349 & 7,90 & & \\
\hline
\end{tabular}

